\title{
Investigation of the Effect of Machining Parameters on Surface Quality in Bamboo
}

\author{
Emrah AYKAC, Sait Dundar SOFUOGLU*
}

\begin{abstract}
The purpose of the study is to obtain optimum processing conditions by investigating the effect of machining parameters of bamboo (Bambusa) material on surface quality. Evaluation was performed for four machining parameters (cutters type, spindle speed, feed rate and depth of cut) and their effects on surface roughness. According to obtained data, roughness values increased with increasing machining depth. Increase in roughness values between $8000 \mathrm{rpm}$ and $10000 \mathrm{rpm}$, decrease in roughness values between $10000 \mathrm{rpm}$ and $14000 \mathrm{rpm}$, and increase in roughness values between $14000 \mathrm{rpm}$ and $16000 \mathrm{rpm}$ was observed. Roughness value increased with increasing cutter feed speed. Roughness value decreased by increasing number of blades in cutter in cutter type. The lowest roughness value was obtained at a machining depth of 2 $\mathrm{mm}$ at a spindle speed of $14000 \mathrm{rpm}$, a feed rate of $1000 \mathrm{~mm} / \mathrm{min}$ and a cutter type 3 (four flute spiral end mill).
\end{abstract}

Keywords: bamboo; machining; surface roughness; wood

\section{INTRODUCTION}

Using wood material for construction purposes has been widely applied for ages. Because of its incomplete supply of wood and escalating environmental awakening for consumers and producers, wood products machining has recently become important. Consequently, optimization of machining process is studied. Current optimization is focused on chip formation, tool wear, wood surface quality, etc. In order to specify economical cost of end product, wood finishing is a substantial parameter. Therefore, surface roughness is used as descriptive feature to evaluate the success of wood finish. Different techniques have been used to measure surface roughness in the area of woodworking. Lumber surface roughness can be used to measure with an airflow method [1]. It is assumed that surface roughness in industrial practices can be handily measured with a light-sectioning shadow scanner method [2]. The stylus technique is commonly used to quantify surface roughness of wood. [3, 4]. Stylus, image analyses were preferred in past studies to qualify the surface quality of solid wood and wood based materials. The stylus tecnique is a mostlly used one in laboratories.

CNC woodworking machineries have been considerably used in the wood and furniture industries. Grooving, milling, and patterning of furniture materials are some usage areas of CNC. This kind of technology offers many benefits with respect to output and surface quality. In was reported that surface roughness increases with worn cutters [5]. Roughness of solid wood using in the woodworking and furniture industries has been investigated. Ilter at all. (2012) reported a study on surface roughness in planing and sanding of Uludag fir [6]. Surface roughness measurements in planing wood materials performed on black locust and walnut was reported by Efe and Gurleyen (2003) [7]. Malkocoglu (2007) investigated surface roughness of oriental beech, Anatolian chestnut, black alder, Scots pine and oriental spruce [8]. Evaluation on surface roughness in composite panels in addition to ten different wood materials was performed by Zhang and Jun (2007) [9]. Škaljić at all. (2009) obtained surface roughness values of planed beech, oak and fir specimens [10]. Sofuoglu (2008) investigated surface quality of larch, poplar, oak and cedar in planing process in various conditions [11]. Hernández and Cool (2008) performed face milling and helical planing in opposite and parallel directions to the fibers on surface of Canada birch wood in various working conditions. They reported that cutting depth had no effect on surface quality and feed rate had an effect on the adhesion resistance and surface smoothness [12]. The effect of machining parameters (feed rate, spindle speed, lateral step and depth of cut) used in CNC milling on MDF sheets was found to have an effect on surface quality [13]. A decrease in surface roughness by increasing speed, and an increase by increasing offset amount, feed speed, and cutting depth in CNC machining of MDF were reported in 14]. In birch wood species, it was observed that feed rate and speed had little effect on surface roughness. It was observed that both feed rate and rotational speed affected $R a$ in ash tree species, while changes in rotational speed of beech were effective on $R a$ [15]. Zhong and Hiziroglu (2013) used particle board used in furniture industry in Singapore, MDF, plywood, needle scanning method for 10 different wood species, and 3D image analyzer. They stated that both methods can be used successfully in furniture production [16]. In the study performed by Sofuogluand Kurtoglu (2015), average roughness values from the highest to the lowest in perpendicular and parallel direction fibers were measured as Lebanon Cedar, black pine, and black poplar, respectively [17]. Optimum point offset machining strategy for CNC machining of massive panel samples produced from Larix was achieved while feed rate was

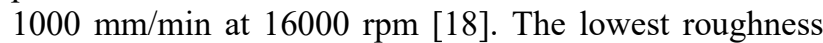
values in massive panel material produced from scotch pine were obtained with cutter 1 , raster machining strategy, $16000 \mathrm{rpm}, 1000 \mathrm{~mm} / \mathrm{min}$ feed rate and $4 \mathrm{~mm}$ depth [19]. Bendikiene and Keturak (2016) obtained roughness values parallel to fibers in birch tree compared to roughness measurements perpendicular to fibers. They suggested a low feed rate for good surface quality [20]. According to results obtained by laser and needle scanning method in beech tree and Ayous tree species, the lowest roughness value was obtained at $2 \mathrm{~m} / \mathrm{min}$ feed rate at $18000 \mathrm{rpm}$ [21]. In the study performed by Bal (2018), as feed rate and blade pitch increased, surface roughness increased, and machining time decreased according to data obtained in medium density fiber board in $\mathrm{CNC}$ machining. It was determined that blade pitch was more effective on surface roughness and machining time than feed rate. In milling, 
cutting speed and feed rate affect roughness. In sanding, sanding particle size was found to be important in surface roughness [22]. Surface roughness was reported as more important in machining perpendicular to fibers [23]. Sedlecký and etc. (2018) studied surface roughness in milling edges using medium density fiberboard (MDF), one side laminated medium density fiberboard and massive spruce panel. More accurate results in measurements were obtained with a non-contact profilometer, but it was long lasting and higher in terms of cost. The best results in terms of surface quality were achieved by reducing feed rate and increasing cutting speed [24]. Isleyen and Karamanoglu (2019) machined medium density fiberboard (MDF) with $\mathrm{CNC}$ in experiments. The effect of axial intersection depth was not statistically significant. A decrease in surface roughness by increasing speed and decreasing feed rate, and an increase in surface roughness by increasing cutter diameter were reported [25]. In machining of massive wood material using modern technology, it is important to determine optimal machining parameters for each wood species using controllable parameters. Bamboo is often used in furniture and interior decoration. Therefore, scopes of this study were organized as the following.

1. Choosing optimum machining parameters (depth of cut, spindle speed, cutter type and feed rate) for Bambusa material.

2. For the machined surface, stylus tracing surface roughness profilometer was used to measure surface roughness $(R a)$ values and statistical software (Minitab) was used to analyze the results.

\section{MATERIAL AND METHODS}

In this study, experiments were carried out by using a Bamboo (Bambusa) wood material that had $7 \mathrm{~mm}$ thickness. Wooden material had a density of $0.607 \mathrm{~g} / \mathrm{cm}^{3}$ at 12\% moisture content ISO 13061-1, ISO 13061-2. Machining of materials was performed with a Scilled CNC machine (Beysantas A.S, Turkey). The experiments were done with four router cutters (Double flute flat end mill, $Z$ $=2$ Double flute spiral end mill, $Z=3$ Three flute spiral end mill, $Z=4$ Four flute spiral end mill was $8 \mathrm{~mm}$ in diameter) (Fig. 1). New and sharp cutters were used in each cutting test. Four machining parameters were used in the experiment and two of them had 3 levels, one of them 2 levels and the other had five levels (Tab. 1).

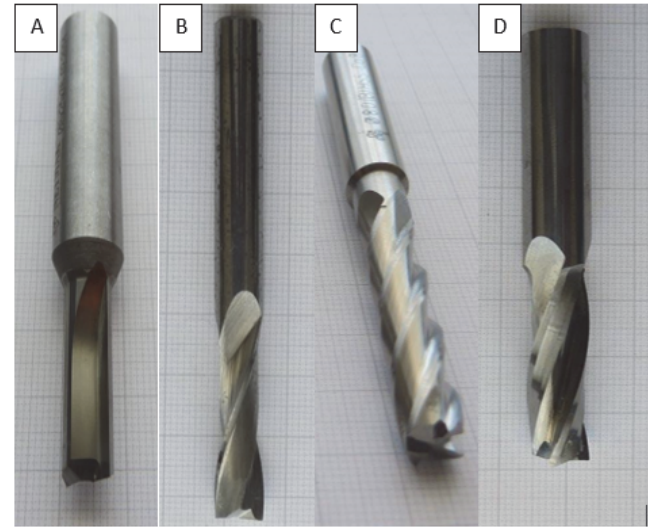

Figure 1 Cemented carpide end mills $A$ - $(Z=2$ Double flute flat end mill, (Netmak) B - $Z=2$ Double flute spiral end mill (Bup) $C-Z=3$ Three flute spiral end mill (Bup), D - Z = 4 Four flute spiral end mill (MakineTakimEndustri A.Ş.).
A $\mathrm{CNC}$ router was used to groove 90 pieces of dimension $50 \times 50 \mathrm{~mm}^{2}$ in total (with raster machining strategy) on panels (Fig. 2a, Fig. 3). Surface roughness measurements were performed in the surface that was to grain at 5 different points for every sample. The measuring parameter $(R a)$ are described in ISO 468 (2009). The standards in ISO 4287 (1997), ISO 3274 (2005) and, ISO 468 (2009) were used to conduct surface roughness measurements. Determination of surface roughness values (Fig. 2b) was performed with Time TR200 (Time Group Inc., China) stylus type profilometer. The pick-up had a 2.5 $\mathrm{mm}$ of tallness; tracing tallness had a $L_{\mathrm{t}}=12.5 \mathrm{~mm}$. Measuring speed, pin diameter and pin top angle of the tool were $10 \mathrm{~mm} / \mathrm{min}, 4 \mu \mathrm{m}$ and $90^{\circ}$, respectively. The temperature of measurement environment was adjusted around $18-22^{\circ} \mathrm{C}$, and there were no vibrations. Calibration process of the tool were performed before measurement, and specified intervals were used to control calibration.

Table 1 Levels designationfor factors
\begin{tabular}{|l|c|c|c|c|c|}
\hline \multicolumn{1}{|c}{$\begin{array}{c}\text { Machining } \\
\text { parameters }\end{array}$} & 1 & 2 & 3 & 4 & 5 \\
\cline { 2 - 6 } Cutter type & $\begin{array}{c}\text { Cutter } 1 \\
\text { (A) }\end{array}$ & $\begin{array}{c}\text { Cutter } 2 \\
\text { (B) }\end{array}$ & $\begin{array}{c}\text { Cutter } 3 \\
\text { (D) }\end{array}$ & & \\
\hline Spindle speed / rpm & 8000 & 10000 & 12000 & 14000 & 16000 \\
\hline Feed rate / mm/min & 1000 & 1500 & 2000 & & \\
\hline Depth of cut / mm & 2 & 4 & & & \\
\hline
\end{tabular}

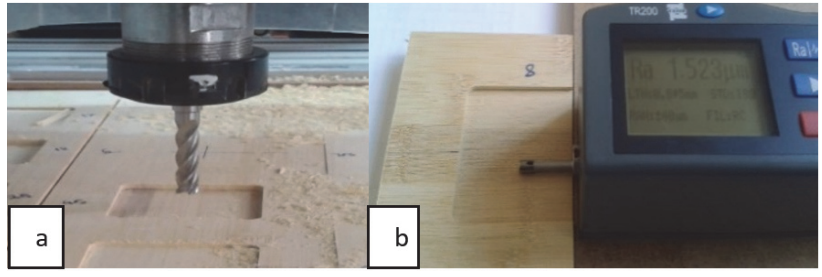

Figure 2a).CNC milling machine (Scilled CNC) b) Surface roughness tester (Time TR - 200).

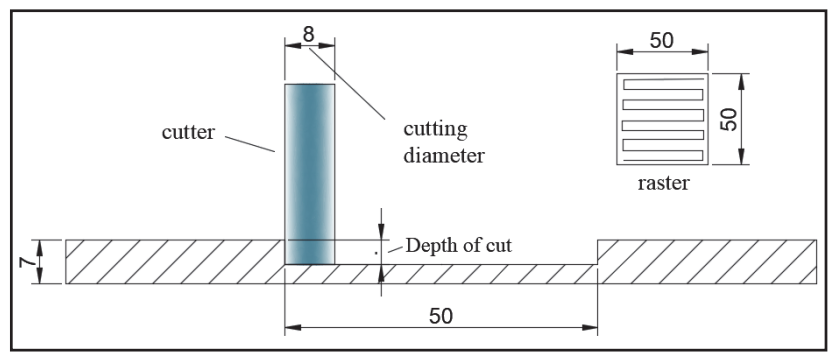

Figure 3 Parameters of CNC process

As a result of machining process, machining with $\mathrm{Z}=$ 3 group spiral end mill was not included in evaluation because of burning and many fiber breaks occurred on surface and excessive rough and defective surfaces are obtained and problems in measuring roughness of surfaces by needle scanning method.

In the evaluation of results, ANOVA (Analysis of variance), and Tukey test were employed.

\section{$3 \quad$ RESULTS AND DISCUSSION}

Experiments were conducted to determine the effect of machining depth, speed, feed rate and cutter type on Ra and evaluated by using statistical methods in the study. Statistical results obtained from the findings are given below. 
According to one-way analysis of variance test applied when the effect of machining depth on $R a$ value was investigated, $P$ value was obtained as 0,299 , according to this, it was seen that there was no statistically significant difference between groups in $95 \%$ confidence level (Tab. 2).

Table 2 One-way ANOVA for the effect of machining depth on $R a$

\begin{tabular}{|l|c|c|c|c|c|}
\hline \multicolumn{1}{|c|}{ Source } & $\begin{array}{c}\text { Degrees of } \\
\text { freedom }\end{array}$ & $\begin{array}{c}\text { Sum of } \\
\text { squares }\end{array}$ & $\begin{array}{c}\text { Mean } \\
\text { square }\end{array}$ & $\begin{array}{c}F \text { (test } \\
\text { value) }\end{array}$ & $P$ \\
\hline $\begin{array}{l}\text { Depth of } \\
\text { cut / mm }\end{array}$ & 1 & 0,4507 & 0,451 & 1,09 & 0,299 \\
\hline Error & 88 & 36,3456 & 0,413 & & \\
\hline Total & 89 & 36,7963 & & & \\
\hline
\end{tabular}

According to one-way analysis of variance test applied to examine the effect of speed on $R a, P$ value was found to be 0,607 at $95 \%$ confidence level, and according to this, there was no statistically significant difference between groups at 95\% confidence level (Tab. 3).

\begin{tabular}{|l|c|c|c|c|c|}
\hline \multicolumn{1}{|c|}{ Table 3 One-way analysis of variance for the effect of speed (rev/min) on $R a$} \\
\hline $\begin{array}{l}\text { Source } \\
\text { Spindle } \\
\text { speed / rpm }\end{array}$ & 4 & 1,141 & 0,285 & 0,68 & 0,607 \\
\hline Error & 85 & 35,655 & 0,4195 & & \\
\hline Total & 89 & 36,796 & & & \\
\hline
\end{tabular}

According to one-way analysis of variance test applied to investigate the effect of feed rate on $R a, P$ value was found as 0,011 at $95 \%$ confidence level, and there was no statistically significant difference between groups (Tab. 4).

\begin{tabular}{|l|c|c|c|c|c|}
\hline \multicolumn{1}{|c|}{ Table 4 One-way analysis of variance for the effect of feed rate on $R a$} \\
\hline Source & $\begin{array}{c}\text { Degrees of } \\
\text { freedom }\end{array}$ & $\begin{array}{c}\text { Sum of } \\
\text { squares }\end{array}$ & $\begin{array}{c}\text { Mean } \\
\text { square }\end{array}$ & $\begin{array}{c}F \text { (test } \\
\text { value) }\end{array}$ & $P$ \\
\hline $\begin{array}{l}\text { Feed rate / } \\
\mathrm{mm} / \mathrm{min}\end{array}$ & 2 & 3,647 & 1,8223 & 4,79 & 0,011 \\
\hline Error & 87 & 33,157 & 0,3810 & & \\
\hline Total & 89 & 36,796 & & & \\
\hline
\end{tabular}

After the analysis of variance was significant, Tukey test was applied and according to the obtained data, it was seen that 1500 and $2000 \mathrm{~mm} / \mathrm{min}$ machining were at same group with 1000 and $1500 \mathrm{~mm} / \mathrm{min}$ at same group and same time in terms of feed rate at $95 \%$ confidence level. At the same time and 1000 and $1500 \mathrm{~mm} / \mathrm{min}$ were at the same group in terms of feed rate at $95 \%$ confidence level.

Tukey test was performed because the analysis of variance was significant. The feed rate of $1500 \mathrm{~mm} / \mathrm{mincan}$ be evaluated in the same group with both $1000 \mathrm{~mm} / \mathrm{min}$ and $2000 \mathrm{~mm} / \mathrm{min}$ feed rate (Tab. 5).

Table 5 Tukey Test for the effect of feed rate $(\mathrm{mm} / \mathrm{min})$ on $R a$

\begin{tabular}{|c|c|c|c|}
\hline Feed rate $/ \mathrm{mm} / \mathrm{min}$ & $\mathrm{N}$ & Mean & Group \\
\hline 2000 & 30 & 2,880 & $\mathrm{~A}$ \\
\hline 1500 & 30 & 2,791 & $\mathrm{~A} \mathrm{~B} \mathrm{~B}$ \\
\hline 1000 & 30 & 2,4159 & B \\
\hline
\end{tabular}

According to one-way analysis of variance test applied to examine the effect of cutter type on $R a, P$ value was found as 0,002 , and according to this, there was statistically significant difference between groups at $95 \%$ confidence level (Tab. 6).

According to the data obtained from Tukey test performed as a result of the analysis of variance, it is seen that cutter number 1 forms a group and cutter number 2 and 3 together form a different group in terms of 95\% confidence level. In other words, there is no significant difference in $R a$ surface roughness at $95 \%$ confidence level in machining with cutter 2 and 3 (Tab. 7).

Table 6 One-way analysis of variance for the effect of cutter type on $R a$

\begin{tabular}{|l|c|c|c|c|c|}
\hline \multicolumn{1}{|c|}{ Source } & $\begin{array}{c}\text { Degrees of } \\
\text { freedom }\end{array}$ & $\begin{array}{c}\text { Sum of } \\
\text { squares }\end{array}$ & $\begin{array}{c}\text { Mean } \\
\text { square }\end{array}$ & $\begin{array}{c}F \text { (test } \\
\text { value) }\end{array}$ & $P$ \\
\hline Cutter type & 2 & 4,978 & 2,4889 & 6,81 & 0,002 \\
\hline Error & 87 & 31,818 & 0,3657 & & \\
\hline Total & 89 & 36,796 & & & \\
\hline
\end{tabular}

Table 7 Tukey test for the effect of cutter type on $R a$

\begin{tabular}{|c|c|c|c|}
\hline Cutter type & $N$ & Mean & Group \\
\hline 1 & 30 & 3,026 & A \\
\hline 2 & 30 & 2,565 & B \\
\hline 3 & 30 & 2,4962 & B \\
\hline
\end{tabular}

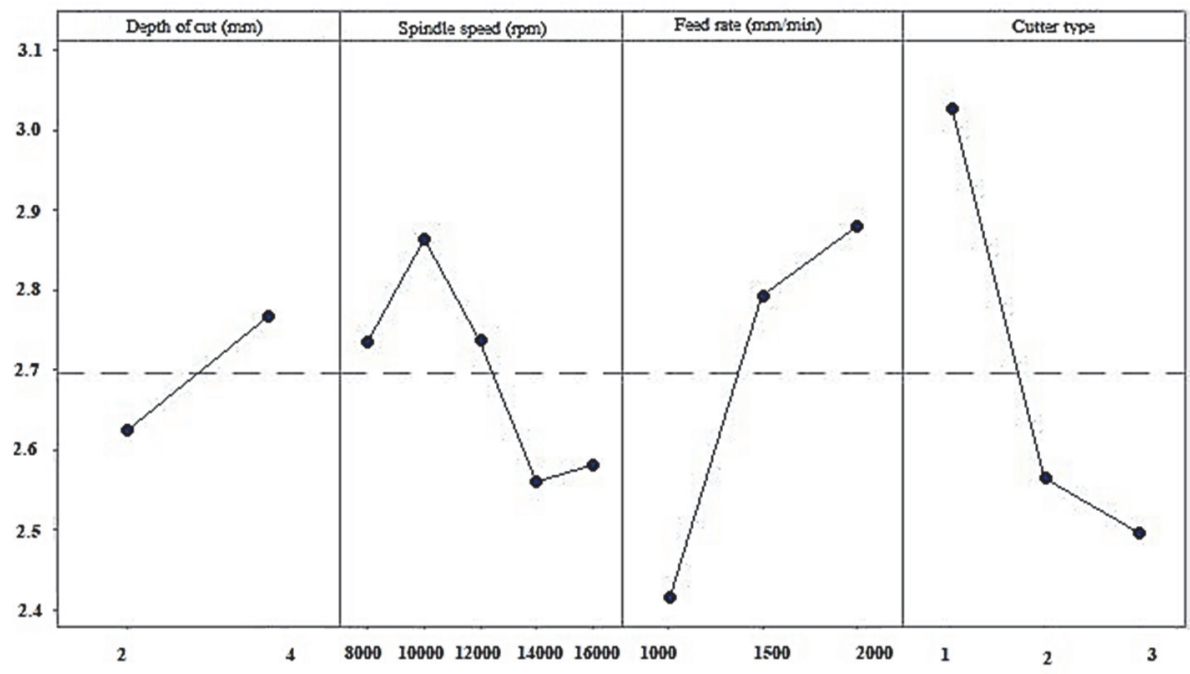

Figure 4 Interactions of machining depth, speed, feed rate, and cutter type in terms of $R a$, main effect graph

According to $R a$ main effect graph, surface roughness increases as the depth of cut increases (Fig. 4). Non-deep cuts give smoother surfaces. Similar results were reported in other studies [14]. A remarkable stabilization was observed for depth of cuts at values $1 \mathrm{~mm}$ and $1.5 \mathrm{~mm}$. It 
is obtained that at higher cutting speeds, the $R a$ values decrease [26].

From the point of view of speed, increasing speed from $8000 \mathrm{rpm}$ to $10000 \mathrm{rpm}$ increased roughness and roughest surfaces occurred. However, with the further increase in speed (12000, $14000 \mathrm{rpm})$, a decrease in $R a$ occurred linearly. However, a small increase in roughness was achieved by increasing the speed to $16000 \mathrm{rpm}$. These unexpected increases or decreases in the linear course can be caused by vibrations in the $\mathrm{CNC}$ at some speed. It can be thought that this situation caused from this reason. When the effect of cutter feed rate on $R a$ is examined, a significant increase in $R a$ value was seen by increasing feed rate from $1000 \mathrm{~mm} / \mathrm{min}$ to $1500 \mathrm{~mm} / \mathrm{min}$., and $\mathrm{Ra}$ value increased by increasing feed rate to $2000 \mathrm{~mm} / \mathrm{min}$, which is the maximum speed of CNC machine, but this increase was slightly lower.Similar results were reported in other studies. An increase in spindle speed and feed rate resulted in a decrease in surface roughness $[10,21,22,26-$ 29]. The surface roughness of MDF increased with lower spindle speed, lower stepover, lower feed rate and lower depth of cut [14].

When the main effect graphs for $R a$ were examined in terms of the cutter type (Fig. 4), the lowest roughness values occurred at a machining depth of $2 \mathrm{~mm}$, at a speed of $14000 \mathrm{rpm}$, a feed rate of $1000 \mathrm{~mm} / \mathrm{min}$ and a cutter type 3 . The highest $R a$ value (the worst surfaces) occurred at a machining depth of $4 \mathrm{~mm}$, at a speed of $10000 \mathrm{rpm}$, a feed rate of $2000 \mathrm{rpm}$ and a cutter type 1.

When cutters are evaluated in terms of surface roughness, the best surface to the roughest surface is 3 (D $=$ Four-flute spiral end mill), 2 ( $\mathrm{B}=$ Double flute spiral end mill), 1 ( $\mathrm{A}=$ Double flute flat end mill) cutters, respectively.

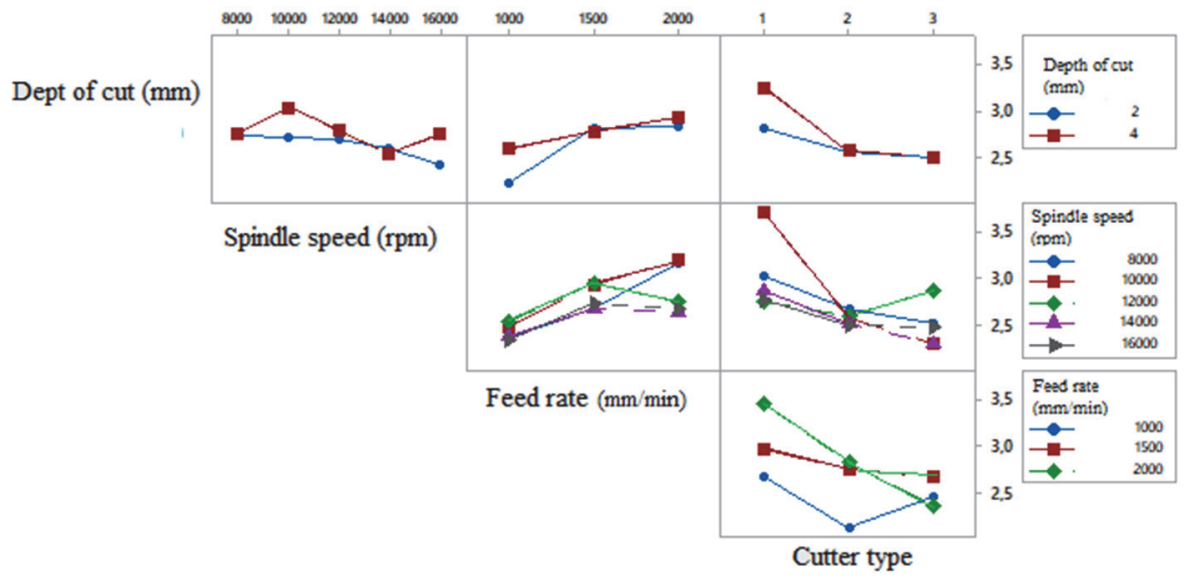

Figure 5 Interactions of machining depth, speed, feed rate, and cutter type in terms of $R a$

In Fig. 5, interactions of machining depth, speed, feed rate and cutter type in terms of $R a$ are shown graphically. In all interactions, it is seen that cutter 1 gives rougher surfaces. Other factors vary, and different situations may occur depending on interacting factor.

\section{CONCLUSION}

The following results can be outlined from the $\mathrm{Ra}$ perspectives, on the basis of the experimental results obtained for the made of Bamboo (Bambusaa):

- It was seen increase in surface roughness by increasing machining depth.

- Increase in cutter speed improves to a certain degree of roughness, and more increase creates rough surfaces.

- An increase in feed rate resulted in an increase in surface roughness $(R a)$, while an increase in spindle speed resulted in a decrease in surface roughness.

- ANOVA results indicated thattype of cutterwas the most dominantparameteraffecting surface roughness. Roughness values of machined surfaces decrease in case of increasing number of blades in cutter.

- Optimal cutting performance (minimum surface roughness) for $R a$ was obtained for Cutter 3, $14.000 \mathrm{rpm}$ spindle speed, $1000 \mathrm{~mm} / \mathrm{min}$ feed rate and $2 \mathrm{~mm}$ depth of the cut.

\section{Acknowledgment}

This work is derived from the master's thesis titled "Investigation of the effect of machining parameters on surface quality in Bamboo" conducted in Kutahya Dumlupinar University, Kutahya Institute of Science and Technology.

\section{REFERENCES}

[1] Porter, A. W., Kusec, D. J., \& Sonders J. L. (1971). Air-flow method measures lumber surface roughness, Canadian Forest Industries, Canada.

[2] Sandak, J. \& Tanaka, C. (1987). Evaluation of surface smoothness using a light-sectioning shadow scanner. Journal of Wood Science, 51(3), 270-273. https://doi:10.1007/s10086-004-0637-z

[3] Peters, C. \& Mergen, A. (1971). Measuring wood surface smoothness: A proposed method. Forest Products Journal, 21(7), 28-30.

[4] Faust, D. T. (1987). Real time measurement of veneer surface roughness by image analysis. Forest Products Journal, 37, 34-40.

[5] Steward, H. A. (1970). Cross grain knife planing, hard maple produces high quality surfaces and flakes. Forest Products Journal, 20, 39-42.

[6] Ilter, E., Camliyurt, C., \& Balkiz, O. D. (2002). Researches on the determination of the surface roughness values of Bornmullerian fir (Abies bornmülleriana Mattf.). Central Anatolia Forestry Research Institute, No: 181, Ankara, Turkey. 
[7] Efe, H. \& Gurleyen, L. (2003). Effects of the cutting direction the number of cutter and rotation value on surface smoothness for some wood species. The Journal of the Industrial Arts Education Faculty of Gazi University, 11-12, 34-44.

[8] Malkoçoğlu, A. (2007). Machining properties and surface roughness of various wood species planed in different conditions. Building and Environment, 42(7), 2562-2567. https://doi:10.1016/j.buildenv.2006.08.028

[9] Jiawei, Z. \& Jun, C. L. S. (2007). A Novel Fusion Technique based Functional Link Artificial Neural Network for LMC Measuring. 2 nd IEEE Conf. Ind. Electron. Appl. (ICIEA 2007), 471-475.

[10] Škaljić, N., Obućina, M., Lučić, R. B., \& Čavlović, A (2009). Effect of feed speed and wood species on roughness of machined surface. Drvna Industrija; 60(4), 229-234.

[11] Sofuoglu, S. D. (2008). Effects of wood machining properties of some native species on surface quality. Istanbul University, Institute of Graduate Studies In Sciences, Doctoral thesis, Istanbul.

[12] Hernández, R. E. \& Cool, J. (2008). Effects of cutting parameters on surface quality of paper birchwood machined across the grain with two planing techniques. Holz als Roh und Werkstoff; 66, 147-154. https://doi:10.1007/s00107-007-0222-4

[13] Karagoz, U. (2010). Investigation of machining parameters on the surface quality in CNC routing wood and wood-based materials. Suleyman Demirel University, Graduate School of Natural and Applied Sciences, Master's thesis, Isparta, Turkey.

[14] Sutcu, A. \& Karagoz, U. (2012). Effect of machining parameters on surface quality after face milling of MDF. Wood Research, 57, 231-240.

[15] Pinkowsk1, G., Szymański, W., \& Nosowski, T. (2012). Analyses of surface roughness in selected wood species after machining on a $\mathrm{CNC}$ woodworking centre. Annals of Warsaw University of Life Sciences-SGGW Forestry and Wood Technology, 79, 164-169.

[16] Zhong, Z., Hiziroglu, S., \& Chan, C. T. M. (2013). Measurement of the surface roughness of wood based materials used in furniture manufacture. Measurement, 46, 1482-1487. https://doi.org/10.1016/j.measurement.2012.11.04

[17] Sofuoğlu, S. D. \& Kurtoğlu, A. (2015). Effects of machining conditions on surface roughness in planing and sanding of solid wood. Drvna Industrija, 66(4), 265-272. https://doi:10.5552/drind.2015.1406

[18] Sofuoglu, S. D. (2015). Determination of optimal machining parameters of massive wooden edge-glued panels made of European larch (Larix decidua Mill.) using Taguchi Design Method. Bio Resources, 10(4), 7772-7781. https://doi:10.15376/biores.10.4.7772-7781

[19] Sofuoglu, S. D. (2017). Determination of optimal machining parameters of massive wooden edge glued panels which is made of Scots pine (Pinus sylvestris L.) using Taguchi design method. European Journal of Wood and Wood Products, 75(1), 33-42. https://doi:10.1007/s00107-016-1028-z

[20] Bendikiene, R. \& Keturakis, G. (2016). The effect of tool wear and planning parameters on birch wood surface roughness. Wood Research, 61(5), 791-798.

[21] Koc, K. H., Erdinler, E. S., Hazir, E., \& Öztürk, E. (2017). Effect of CNC application parameters on wooden surface quality, Measurement, 107, 12-18. https://doi:10.1016/j.measurement.2017.05.001

[22] Bal, B. C. (2018). The effects of some tool paths adjustments of CNC machines on surface roughness and processing time of fiberboards. Furniture and Wooden Material Research Journal, 1(2), 21-30.

[23] Kúdela, J., Mrenica, L., \& Javorek, L. (2018). The influence of milling and sanding on wood surface morphology. Acta Facultatis Xylologiae Zvolen, 60(1), 71-83.

[24] Sedlecký, M., Kvietková, M., \& Kminiak R. (2018). Medium-density fiberboard (MDF) and edge-glued panels (EGP) after edge milling-Surface roughness after machining with different parameters. BioResources, 13(1), 2005-2021. https://doi.10.15376/biores.13.1.2005-2021.

[25] Isleyen, U. K. \& Karamanoglu, M. (2019). The Influence of Machining Parameters on Surface Roughness of MDF in Milling Operation. BioResources, 14(2), 3266-3277.

[26] De Deus, P. R., Alves, M. C. de S., \& Vieira F. H. A. (2015). The quality of MDF workpieces machined in CNC milling machine in cutting speeds, feedrate, and depth of cut. Meccanica, 50, 2899-2906. https://doi:10.1007/s11012-015-0187-z.

[27] Zhong, Z. W., Hiziroglu, S., \& Chan, C. T. M. (2013). Measurement of the surface roughness of wood based materials used in furniture manufacture. Measurement, 46(4), 1482-1487. https://doi.org/10.1016/j.measurement.2012.11.041

[28] Davim, J. P., Clemente, V. C., \& Silva, S. (2009). Surface roughness aspects in milling MDF (medium density fibreboard). International Journal of Advanced Manufacturing Technology, 40, 49-55. https://doi:10.1007/s00170-007-1318-z

[29] Braga, P. P. C., Silva, J. R. M., Néri, A. C., Calegário, N., \& Lima, J. T. (2014). Qualidade da superfície de madeira de Coffea arábica. Cerne, 20, 21-28. https://doi:10.1590/S0104-77602014000100003

\section{Contact information:}

\section{Emrah AYKAC, MSc}

Kutahya Dumlupinar University,

Institute of Science Studies,

Kutahya, Turkey

E-mail: emrahaykac34@gmail.com

Sait Dundar SOFUOGLU, Assoc. Prof. Dr.

(Corresponding author)

Kutahya Dumlupinar University,

Simav Technology Faculty,

Wood Works Industrial Engineering Department,

43500, Simav, Kutahya, Turkey

E-mail: sundar.sofuoglu@dpu.edu.tr 